\title{
Social-Emotional Health and Psychological Well-Being among Church School Students
}

\author{
Eva Gajdošová - Jana Janičová ${ }^{*}$
}

\author{
Received: December 13, 2020; received in revised form: March 3, 2021; \\ accepted: March 5, 2021
}

\begin{abstract}
:
Introduction: This study aims to determine the level of social-emotional health of church school students and relationships among the variables of social-emotional health and psychological well-being.

Methods: The research group consisted of 73 church school students in Presov Region. The data collection tools were the Social - Emotional Health Survey for secondary education (SEHS-S) and the Scale of Psychological Well-Being (PWB). The presented quantitative study has a correlation character with the comparative questions and exploratory verification design.
\end{abstract}

Results: The findings of the study showed that there is a strong positive correlation between overall social-emotional health referred to covitality and psychological well-being. Strong and moderate correlations were found among domains and psychological indicators of social-emotional health and dimensions of psychological well-being. A domain belief in others strongly correlates with positive relations with others. A strong correlation has been found between the indicator of peer support and the dimension of positive relations with others. The findings showed a moderately large, statistically significant difference in the level of belief in self in favor of males compared to females. Small and medium-sized differences between males and females were also found at the level of psychological indicators. The level of overall social-emotional health increases with the increase in the mastery of the environmental mastering and positive relations with others, which explains $35 \%$ of the data variance.

Discussion: Research indicates relationships between the social-emotional health and psychological well-being as well as among dimensions, domains and indicators. The results support previous findings of other authors. Furthermore, the results showed a significant difference in the level of belief in self domain in favour of males compared to females. This

\footnotetext{
* Eva Gajdošová, Pan-European University in Bratislava, Faculty of Psychology, Bratislava, Slovakia; eva.gajdosova@paneurouni.com Jana Janičová, Pan-European University in Bratislava, Faculty of Psychology, Bratislava, Slovakia; janicova@yahoo.com
} 
finding indicates that males have higher self-confidence while compared to females.

Limitations: There are certain limitations in the research, which include usage of non-standardized methods on Slovak population and a low level of reliability for Psychological Well-being Scale. Among other limitations, we include the time of data collection, which took place during the last class at the end of the week.

Conclusion: Mental Health is about more than mental illness. Being mentally healthy and feeling well is important. To measure and identify elements of mental health may be useful to comprehend and promote psychological strengths of a person. A value of the paper lies in findings concerning social-emotional health of church school students, which contributed to the standardization of SEHS-S in Slovakia. Nevertheless, social-emotional health of Slovak students should not be neglected and further research on a larger sample is needed.

Key words: mental health, social-emotional health, psychological wellbeing.

\section{Introduction}

\section{Mental Health}

Mental health is an integral and essential component of health, one cannot exist without the other (Damodaran \& Paul, 2016). According to World Health Organization (2004) a health is a state of complete physical, mental and social well-being, not merely the absence of disease or infirmity. Mental health is more than the absence of mental disorders and it is closely connected to physical health (Kolappa et al., 2013). It is a state of well-being, in which an individual realizes own abilities, is able to cope with stress in life, works productively and is capable to make a contribution to the community (WHO, 2004).

Traditionally, One-Dimensional Model perceived mental health as the absence of mental illness (Furlong et al., 2013). Through the lens of the absence of psychopathology (Keyes et al., 2002) improvement occurs due to the absence of mental deficit (Moore et al., 2018). Mental health and mental illness are put on two opposite poles of a continuum, the research of mental health sets bounds to the psychopathology and is focused on mental disorder (Keyes, 2002).

According to the Dual-Factor Model of Mental Health, mental illness and mental wellness do not create a continuum of illness on one end and wellness on the other, but rather complement each other (Dowdy et al., 2014). The Dual-Factor Model or Two Continua Model emphasizes that positive (e.g., subjective wellbeing, positive strengths) and negative (e.g., distress) indicators of mental health are related but distinct, and the absence of pathology does not necessarily mean a good state of mental health (Suldo \& Shaffer, 2008). 


\section{Acta Educationis Generalis \\ Volume 11, 2021, Issue 2}

A Social-Emotional Health is a sum of positive social and emotional dispositions of a person and it is in line with the dual mental health approach. The aim of the Model of Social-Emotional Health by Michel Furlong is to identify key positive indicators for predicting mental health (Furlong et al., 2014). The SocialEmotional Health Survey system was developed to measure the components of covitality latent structure. It is based on positive psychology, consists of 4 positive main domains and 12 subscales as psychological indicators of mental health. The belief in self domain consists of self-efficacy, persistence and selfawareness. The belief in others domain comprises of family support (Tamášová \& Kušnieriková, 2018), institutional support and peer support. Emotional competences consist of cognitive reappraisal, empathy, self-regulation, and the last domain, engaged living, includes gratitude, zest and optimism. The overall Social-Emotional Health is referred to covitality. The Social-Emotional Health Survey (SEHS) has a version for primary, secondary and a higher education (Furlong et al., 2014; You et al., 2013).

\section{SEHS - S}

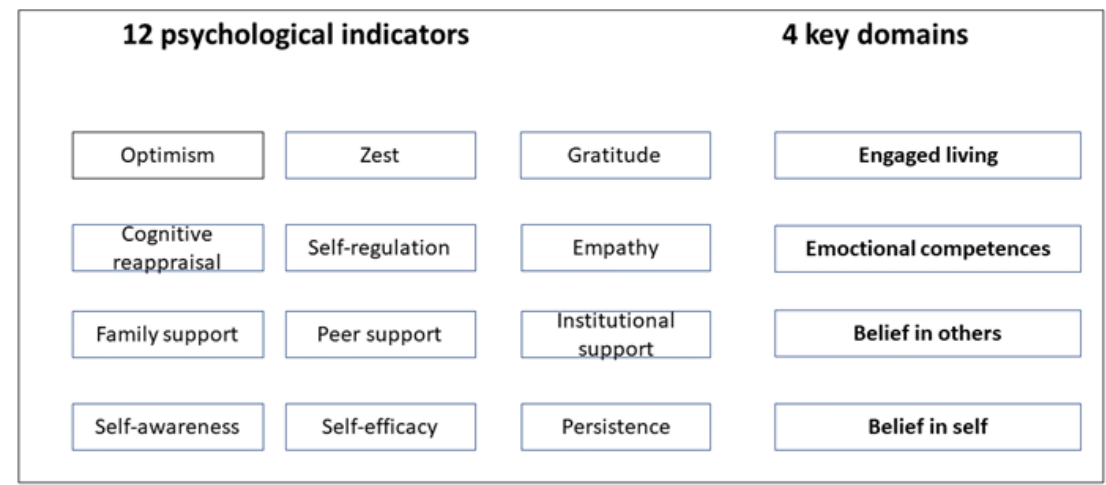

Figure 1. Model of Social-Emotional Health Survey-Secondary (SEHS-S).

\section{Well Being}

Well-being is a multidimensional construct which refers to the optimal experience and human functioning. Ed Diener's Subjective Well-Being (SWB) is understood in terms of life satisfaction and a balance of positive and negative emotional states. It is defined by how people cognitively and effectively evaluate their lives. It consists of two components: an emotional and a cognitiveevaluative. The emotional component consists of positive and negative emotions. The cognitive-evaluative includes general satisfaction with life (Diener, Oishi, \& Lucas, 2003). Carol Ryff's Psychological well-being is 


\section{Acta Educationis Generalis \\ Volume 11, 2021, Issue 2}

defined in terms of human's involvement in addressing existential challenges and life issues. This eudaimonic approach perceives well-being as a consequence of overall psychological actualization from which a person develops its own full potential (Vázquez et al., 2009), is based on the concept of human development and existential challenges (Keyes et al., 2002), and it is related to long-term lasting happiness (Opree et al., 2018). Psychological well-being is determined by 6 aspects: self-acceptance; purpose in life; environmental mastery; positive relationships; personal growth; and autonomy (Henn at al., 2016). A person achieves psychological well-being if optimally fulfils all 6 areas that are its sources and direct components (Ryff, 1995). This paper deals with psychological well-being.

The aim of our research was to find the relationships between the socialemotional health and psychological well-being among church school students at the level of covitality, domains (VO1) and psychological indicators (VO2). We gathered evidence for empirical support for the hypothesis (H1) about the positive relationship between covitality and psychological well-being (Furlong, 2013; Boman et al., 2017; Telef \& Furlong, 2017), as well as for hypothesis about the different level of social-emotional health among males and females (H2) (Furlong et al., 2014; Radnoti, 2016). We tried to identify the most significant model which explains the most percent variability of covitality (VO3).

\section{Methods}

\subsection{Participants}

The research group consisted of 73 participants of the 3rd and 4th year of church school in Prešov Region. The data was collected in October 2019. The majority of participants, totally $39(54.2 \%)$ were females, and 33 males $(45.8 \%)$ aged from 17 till 19 years old $(\mathrm{M}=17.5, \mathrm{SD}=.605)$. More than half of the participants is living in the village (58.3\%), less than half comes from the city $(41.7 \%)$. As many as $86.1 \%$ participants are from complete and $12.5 \%$ of incomplete families.

\subsection{Measures}

To measure the social-emotional health in our research, we decided to use the Social-Emotional Health Survey (SEHS-S) for secondary education. The 36item self-reported, strengths-based measure is to assess 12 positive socialemotional psychological dispositions among students, three items per construct referred as the main domain. The overall Social- emotional health is referred to construct called covitality, which is conceptualized as the synergistic effect of positive mental health (Furlong et al., 2014). Theoretical score range of the instrument is from 36 till 148. Students respond to each of 36 items using a 4point Likert Scale. Previous studies have supported good psychometric quality 
of SEHS-S, internal consistency has been consistent (Furlong et. al, 2014; You et al., 2013; Boman et al., 2017; Timofejova et al., 2016; Radnoti, 2016; Gajdošová et al., 2018).

The internal consistency of SEHS-S questionnaire within our research group is at high level of Crombach alpha for a total score across items $\alpha=.852$, for main domains belief in self $\alpha=.747$, belief in others $\alpha=.760$, emotional competences $\alpha=.770$, and engaged living $\alpha=.834$. For psychological indicators subscales there is a following internal consistency: self-efficacy $\alpha=.662$, self-awareness $\alpha=.730$, persistence $\alpha=.505$, institutional support $\alpha=.728$, family support $\alpha=.871$, peer support $\alpha=.914$, cognitive reappraisal $\alpha=.535$, empathy $\alpha=.867$, self-regulation $\alpha=.518$, optimism $\alpha=.852$, gratitude $\alpha=.683$, zest $\alpha=.874$.

Carol D. Ryff's Scale of Psychological Well-Being was used to assess psychological well-being. The instrument consists of 18 statements mapping 6 areas. Participants follow the 7-point Likert Scale. The theoretical score range is from 18 till 126 (Ryff \& Singer, 1998). The internal consistency is at an acceptable level $\alpha=.754$. Cronbach alpha for dimensions is following: positive relationships $\alpha=.480$, self-acceptance $\alpha=.742$, autonomy $\alpha=.451$, personal growth $\alpha=.548$, environmental mastery $\alpha=.606$. The lowest level of reliability was verified for the purpose in life $(\alpha=.280)$. If we had removed item number 10 , reliability would have increased to $\alpha=.633$, because it negatively correlates with the rest.

Presented quantitative research has a correlation character with the comparative questions, and exploratory-verification design.

\section{Findings}

\subsection{Social-emotional health and psychological well-being}

There is a strong positive correlation between covitality and psychological wellbeing ( $\mathrm{rs}=0.608, \mathrm{p}<.01$ ), between covitality and positive relations with others $(\mathrm{rs}=0.528, \mathrm{p}<.01)$ as well as between covitality and self-acceptance $(\mathrm{rs}=0.550$, $\mathrm{p}<.01)$. Moderate correlation was found between covitality and environmental mastering $(\mathrm{rs}=0.395, \mathrm{p}<.01)$ and covitality and personal growth $(\mathrm{rs}=0.316$, $\mathrm{p}<.01)$. Between covitality and autonomy $(\mathrm{rs}=0.284 \mathrm{p}<.05)$ as well as covitality and purpose in life $(\mathrm{rs}=0.229, \mathrm{p}<.05)$ there has been weak correlations manifested. Correlations are presented in Table 1. 
Table 1

The correlation matrix of the social-emotional health: covitality and psychological well-being $P W B$, dimensions included: positive relations with others (PR), self-acceptance (SAC), autonomy (A), personal growth $(P G)$, environmental mastering (EM), purpose in life (PL) within the research group $(N=72)$

\begin{tabular}{|c|c|c|c|c|c|c|c|}
\hline $\begin{array}{l}\text { Spearman's rho } \\
\text { covitality }\end{array}$ & $\begin{array}{l}P W B \\
.608^{* *}\end{array}$ & $\frac{P R}{.528 * *}$ & $\frac{S A C}{.550 * *}$ & $\begin{array}{l}A \\
.284 *\end{array}$ & $\frac{P G}{316^{* *}}$ & $\frac{E M}{395 * *}$ & $\frac{P L}{.229}$ \\
\hline
\end{tabular}

There is a strong positive correlation manifested between belief in others and positive relations with others $(\mathrm{rs}=0.516, \mathrm{p}<.01)$. Correlations between emotional competencies and self-acceptance $(\mathrm{rs}=0.470, \mathrm{p}<.01)$, emotional competencies and personal growth $(\mathrm{rs}=0.372, \mathrm{p}<.01)$ and between emotional competencies and environmental mastering $(\mathrm{rs}=0.307, \mathrm{p}<.01)$ have been manifested as moderate. Belief in self moderately correlates with self-acceptance $(\mathrm{rs}=0.383, \mathrm{p}<.01)$ as well as environmental mastering ( $\mathrm{rs}=0.334, \mathrm{p}<.01)$. Moderate correlation has been found between engaged living and positive relations with others ( $\mathrm{rs}=0.301$, $\mathrm{p}<.05$ ). All other correlations were low or very low. Correlations between domains of SEHS-S and dimensions of PWB are presented in Table 2.

Table 2

The correlation matrix of main domains of SEHS-S: belief in self (BS), belief in others $(B O)$, emotional competencies (EC), engaged living (EL) and dimensions of PWB Scale: positive relations with others (PR), self-acceptance (SAC), autonomy $(A)$, personal growth $(P G)$, environmental mastering $(E M)$, purpose in life (PL) within the research group $(N=72)$

\begin{tabular}{|c|c|c|c|c|c|c|}
\hline Spearman's rho & $\underline{P R}$ & $\underline{S A C}$ & $\underline{A}$ & $\underline{P G}$ & $\underline{E M}$ & $\underline{P L}$ \\
\hline BS & .210 & $.383^{* *}$ & .153 & $.158^{* *}$ & $.334 * *$ & $.241 *$ \\
\hline BO & $.516^{* *}$ & .227 & .036 & .053 & $.248^{*}$ & .064 \\
\hline EC & .221 & $.470^{* *}$ & .119 & $.372^{* *}$ & $.307^{* *}$ & .177 \\
\hline EL & $.301 *$ & .205 & .252 & .189 & $.235^{*}$ & .095 \\
\hline
\end{tabular}

${ }^{*} \mathrm{p}<0.05, * * \mathrm{p}<0.01$

Further analysis showed correlations among psychological indicators of SEHS-S and dimensions of PWB. There is a strong positive correlation between positive relations with others and peer support $(\mathrm{rs}=0.506, \mathrm{p}<.01)$ and a moderate positive correlation between positive relations with others and subscales family support $(\mathrm{rs}=0.440, \mathrm{p}<.01)$, self-awareness $(\mathrm{rs}=0.358, \mathrm{p}<.01)$ and gratitude $(\mathrm{rs}=0.336$, $\mathrm{p}<.01)$. Moderate positive correlations have been found between self-acceptance and cognitive reappraisal $(\mathrm{rs}=0.479, \mathrm{p}<.01)$, self-regulation $(\mathrm{rs}=0.447, \mathrm{p}<.01)$ 
and self-efficacy ( $\mathrm{rs}=0.349, \mathrm{p}<.01)$. According to the further analysis, we found that, there is a weak correlation between autonomy and subscales of self-efficacy $(\mathrm{rs}=0.241, \mathrm{p}<.005)$, gratitude $(\mathrm{rs}=0.241)$ and zest $(\mathrm{rs}=0.216)$. Personal growth moderately positively correlates with self-efficacy ( $\mathrm{rs}=0.326, \mathrm{p}<.01)$, cognitive reappraisal $(\mathrm{rs}=0.315, \mathrm{p}<.01)$ and self-regulation $(\mathrm{rs}=0.360, \mathrm{p}<.01)$. There is a weak negative correlation between personal growth and peer support $(\mathrm{rs}=-$ 0.146). Environmental mastering moderately, positively correlates with selfregulation ( $\mathrm{rs}=0.400, \mathrm{p}<.01)$, family support $(\mathrm{rs}=0.381, \mathrm{p}<.01)$, cognitive reappraisal $(\mathrm{rs}=0.381, \mathrm{p}<.01)$ and self-efficacy $(\mathrm{rs}=0.337, \mathrm{p}<.01)$. Other correlations were weak or negligible. Correlations among psychological indicators of SEHS-S and dimensions of PWB are presented in Table 3.

Table 3

The correlation matrix of psychological indicators of SEHS-S: Self-efficacy (SE), Self-awareness (SA), Persistence (PE), Institutional support (IS), Family support (FS), Peer support (PS), Cognitive reappraisal (CR), Empathy (E), Selfregulation (SR), Optimism $(O)$, Gratitude $(G)$, Zest $(Z)$ and dimensions of PWB Positive relations with others (PR), Self-acceptance (SAC), Autonomy (A), Personal Growth (PG), Environmental Mastery (EM), Purpose in life (PL)within research group $(N=72)$

\begin{tabular}{|c|c|c|c|c|c|c|}
\hline Spearman's rho & $\underline{P R}$ & $\underline{S A C}$ & $\underline{A}$ & $\underline{P G}$ & $\underline{E M}$ & $\underline{P L}$ \\
\hline SE & .183 & $.349^{* *}$ & $.241 *$ & $.326 * *$ &.$\overline{337} * *$ & .080 \\
\hline $\mathbf{S A}$ & $.358 * *$ & $.273 *$ & .098 & .072 & $.295 *$ & .154 \\
\hline PE & -.098 & $.265 *$ & .085 & .062 & .125 & $.241 *$ \\
\hline IS & .137 & .214 & .118 & .152 & .126 & .148 \\
\hline FS & $.440^{* *}$ & .208 & .109 & .093 & $.381 * *$ & .099 \\
\hline PS & $.506^{* *}$ & .135 & -.007 & -.146 & .038 & -.220 \\
\hline CR & .158 & $.479^{* *}$ & .161 & $.315 * *$ & $.381 * *$ & -.056 \\
\hline $\mathbf{E}$ & .081 & .180 & .115 & $.240 *$ & -.023 & .226 \\
\hline SR & .202 & $.447 * *$ & .080 & $.360 * *$ & $.400 * *$ & .216 \\
\hline $\mathbf{O}$ & $.271 *$ & .182 & .093 & .055 & .199 & .015 \\
\hline $\mathbf{G}$ & $.336^{* *}$ & .198 & .241 & $.247 *$ & .190 & $.291 *$ \\
\hline $\mathbf{Z}$ & .094 & .103 & .216 & .137 & .153 & -.024 \\
\hline
\end{tabular}

\subsection{Social-emotional health and gender}

Males within the research group reached a level of higher average of socialemotional health $(\mathrm{Mdn}=108.67, \mathrm{IQR}=8.33)$, females scored at a level of lower average $(\mathrm{Mdn}=104.00, \mathrm{IQR}=5.00)$. There is a small size effect of the difference between males and females within the overall level of social-emotional health $(\mathrm{rm}=.219)$, close to being statistically significant $(\mathrm{U}=480.50, \mathrm{p}=.065)$. There are small and medium effect size of the differences within dimensions between the group of males and the group of females. Both genders reached a medium level 


\section{Acta Educationis Generalis \\ Volume 11, 2021, Issue 2}

of belief in self domain, but males $(\mathrm{Mdn}=26.86, \mathrm{IQR}=5.00)$ scored higher compared to females $(\mathrm{Mdn}=23.29, \mathrm{IQR}=7.00)$, medium effect size of the difference between the groups, a result has statistical significance $(\mathrm{rm}=.333$, $\mathrm{U}=396.00, \mathrm{p}=.005$ ). Within the belief in others domain high level of socialemotional health were shown among both genders, females $(\mathrm{Mdn}=30.00$, $\mathrm{IQR}=7.00)$ and males $(\mathrm{Mdn}=28.67, \mathrm{IQR}=5.00)$, with a small effect size difference $(\mathrm{rm}=.104)$, not statistically significant $(\mathrm{U}=566.50, \mathrm{p}=.382)$. Females showed high level of social-emotional health within emotional competencies $(\mathrm{Mdn}=27.86, \mathrm{IQR}=7.00)$, males scored higher $(\mathrm{Mdn}=28.20, \mathrm{IQR}=5.00)$ with a small effect size difference $(\mathrm{rm}=.097)$, not statistically significant $(\mathrm{U}=571.50$, $\mathrm{p}=.414$ ). Males showed high level of social-emotional health within the domain belief in others $(\mathrm{Mdn}=28.67, \mathrm{IQR}=5.00)$ and emotional competencies $(\mathrm{Mdn}=28.20, \mathrm{IQR}=5.00)$. For both domains, belief in self $(\mathrm{Mdn}=26.86$, $\mathrm{IQR}=5.00)$ and engaged living $(\mathrm{Mdn}=26.33, \mathrm{IQR}=7.50)$, males scored at the medium level of social-emotional health. Females showed the highest, high level of social-emotional health for the domain belief in others $(\mathrm{Mdn}=30.00$, $\mathrm{IQR}=7.00)$. For the emotional competencies $(\mathrm{Mdn}=27.86, \mathrm{IQR}=7.00)$, engaged living ( $M d n=24.09, I Q R=9.00)$ and belief in self $(M d n=23.29, \quad I Q R=7.00)$ females scored at the medium level of social-emotional health.

\subsection{Regression analysis of social-emotional health and psychological well- being}

The stepwise selection algorithm was used to choose the best subset of variables model between covitality and psychological well-being. Within the regression model, the covitality was determined as a dependent variable, and for predictors were chosen two variables: environmental mastering and positive relations with others. Based on the findings, we state that with the higher level of environmental mastering and positive relations with others the level of covitality increases. The regression model with two independent variables together explains $35 \%$ of variability of covitality. The level of overall social-emotional health increases with the increase in the mastery of the environment and positive relationships with others, which explains $35 \%$ of the data variance.

\section{Table 4}

\begin{tabular}{|c|c|c|c|c|}
\hline model & $\underline{R}$ & $\underline{R 2}$ & $\underline{R 2 \text { adj }}$ & Std. Error of the Estimate \\
\hline 1 & $.480 \mathrm{a}$ & .231 & .220 & 11.76 \\
\hline 2 & $.592 \mathrm{~b}$ & .350 & .331 & 10.89 \\
\hline
\end{tabular}


Table 5

\begin{tabular}{|c|c|c|c|c|c|}
\hline \multirow{3}{*}{ Model } & Unstandardized & & Standarized & $t$ & $\underline{p}$ \\
\hline & Coefficients & & $\overline{\text { Coefficients }}$ & & \\
\hline & $B$ & Std.Error & Beta & & \\
\hline Constant & $82.5 \overline{50}$ & 5.149 & & 16.031 & .000 \\
\hline $\begin{array}{l}\text { Environmental } \\
\text { mastering }\end{array}$ & 1.879 & .413 & .480 & 4.549 & .000 \\
\hline Constant & 66.369 & 6.611 & & 10.039 & .000 \\
\hline Environmental & 1.465 & .400 & .375 & 3.664 & .000 \\
\hline mastering & 1.426 & .403 & .361 & 3.533 & .001 \\
\hline $\begin{array}{l}\text { Positive relations } \\
\text { with others }\end{array}$ & & & & & \\
\hline
\end{tabular}

a. Dependent Variable: covitality

\section{Discussion}

The aim of the study was to determine the relationships between the socialemotional health and the psychological well-being among students of Church School. We found out that there is a strong positive relationship between covitality and psychological well-being (H1). The results of the present study are consistent with the findings of other authors (Furlong et al., 2013; Renshaw et al., 2014; Boman et al., 2017; Telef \& Furlong, 2017). It can be stated that young people who have higher levels of social-emotional health could experience higher level of psychological well-being. The results of the present study further revealed that there is a strong positive relationship (VO1) between covitality and positive relations with others, and self-acceptance. It can be stated, that students with better relationships with others are of more self-acceptance and they are mentally healthier. The results further revealed moderately strong relationships between Covitality and environmental mastering as well as between Covitality and personal growth. Between covitality and autonomy, as well as covitality and purpose in life there have been shown week relations. The results are consistent with the findings of research of other authors Bomana et al. (2017).

There is a strong relationship between belief in others and positive relations with others. These results suggest that students who trust others tend to have better relationships. We found moderately strong relationships between emotional competencies and self-acceptance, between emotional competencies and personal growth, as well as between emotional competencies and environmental mastering. There are positive relationships between psychological indicators of social-emotional health and dimensions of psychological well-being. (VO2) The strong positive relationship has been revealed between the indicator of peer support and the dimension of positive relations with others. Moderately strong 
relationships of positive relations with others were shown also among indicators of family support, gratitude and self-awareness. It can be believed that adolescents who receive family support, are grateful and self-aware, have better relationships with others. The results of the present study are partly consistent with the findings of the study of other authors (Gajdošová et al., 2018; Timofejová et al., 2016; Gálová \& Veselková, 2012).

The results also revealed that there were moderately strong relationships between self-acceptance and cognitive reappraisal, between self-acceptance and self-regulation, as well as between self-acceptance and self-efficacy. According to the results of our study, young people who have a high level of selfacceptance are able to regulate their own emotions, are of higher self-control and self-efficacy.

Moderately strong relationships have been shown within the personal growth dimension, which is most related to self-regulation, self-efficacy and cognitive reappraisal.

As to environmental mastering, there have been shown moderately strong relationships with self-regulation, cognitive reappraisal, family support as well as self-efficacy. Within the dimension of autonomy, there have been week relationships shown only.

As to the domain belief in self males and females scored at the medium level of social-emotional health, the effect size difference between the higher level of male's and lower level of the female's group is medium and statistically significant (H2). As stated, females have significantly lower levels of belief in self compared to the opposite gender. The results showed a significant difference in the level of self-confidence in favor of males compared to females. These findings are consistent with the findings of other authors (Furlong, et al., 2014; Radnoti, 2016; Gajdošová et al., 2018), who pointed out at a higher level of belief in self among males.

Furthermore, the level of overall social-emotional health increases with the increase in the mastery of the environment and positive relationships with others, which explains $35 \%$ of the data variance (VO3).

\section{Conclusion}

However, the findings should be interpreted in the light of limits, which include the usage of non-standardized methods on Slovak population, low level of reliability for Psychological Well-being Scale, the time of data collection, which took place during the last class at the end of the week. Validation of internal consistency of both instruments could be considered as the key benefit of the research as well as our contribution to the standardization of SEHS-S questionnaire in Slovakia. 


\section{Acta Educationis Generalis \\ Volume 11, 2021, Issue 2}

\section{Acknowledgement}

The contribution was created within the solution of the scientific project GA/1/2019 Social-emotional health of students as an important indicator of the quality of school, Grant Agency of Academia aurea, Ostrava, Czech Republic (2019-2021).

\section{References}

Boman, P., Mergler, A., \& Pennell, D. (2017). The effects of covitality on well-being and depression in Australian high school adolescents. Clinical Psychiatry, 3(2), 1-4.

Damodaran, D. K., \& Paul, V. K (2016). Gender and mental health: Are there differences? The International Journal of Indian Psychology, 3(2), 190-199.

Diener, E., Oishi, S., \& Lucas, R. E. (2003). Personality, culture, and subjective wellbeing: Emotional and cognitive evaluations of life. Annual Review of Psychology, 54(1), 403-425.

Dowdy, E., Furlong, M. J., Raines, T. C., Bovery, B., Kauffman, B., Kamphaus, R. W., Dever, B. V., Price, M., \& Murdock, J. (2014). Enhancing school-based mental health services with a preventive and promotive approach. Universal screening for complete mental health. Journal of Educational and Psychological Consultation, 25(2-3), 178-197.

Furlong, M., You, S., Renshaw, T., Smith, D., \& O’Malley, M. (2013). Preliminary development and validation of the Social Emotional Health Survey for secondary school students. Springer Science + Business Media Dordrecht, 117(23), 1011-1032.

Furlong, M. J., Gilman, R., \& Huebner, E. S. (Eds.). (2014). Covitality: A Synergistic Conception of Adolescents Mental Health. Handbook of Positive psychology in the Schools. New York: Routledge/Taylor\&Francis.

Gajdošová, E., Radnoti, E., \& Bisaki, V. (2018) Sociálno-emocionálne zdravie a prežívanie štastia $u$ študentov stredných škôl. Bratislava: PEVŠ.

Gálová, L., \& Veselková, D. (2012). Psychologický well-being u mladých dospelých venujúcich sa dobrovol'níckej činnosti. In Sbornik príspěvkü: 1. Konference pozitivní psychologie v České republice, 23.-24. 5. 2012, Brno.

Henn, C. M., Hill, C., \& Jorgensen, L. I. (2016). An investigation into the factor structure of the Ryff Scales of Psychological Well-being. SA Journal of Industrial Psychology, 42(1), 1275.

Keyes, C. L., Shmotkin, D., \& Ryff, C. D. (2002). Optimizing well-being: The empirical encounter of two traditions. Journal of Personality and Social Psychology, 82(6), 10071022 .

Kolappa, K., Henderson, D. C., \& Kishore, S. P. (2013). No physical health without mental health: Lessons unlearned? Bulletin of the World Health Organization, 91(3), 3A.

Moore, S. A., Dowdy, E., Nylund-Gibsonb, K., \& Furlong, M. J. (2018). A latent transition analysis of the longitudinal stability of dual factor mental health in adolescence. Journal of School Psychology, 73, 56-73.

Opree, S., Buijzen, M., \& Reijmersdal, E. A. (2018). Development and validation of the Psychological Wellbeing Scale for children (PWB-c). Societies, 8(18), 2-14.

Radnóti, E. (2016). Mentálne zdravie v školách v kontexte kvality školy (Doctoral Thesis). Bratislava: PEVŠ, Fakulta psychológie, Ústav školskej a pracovnej psychológie.

Renshaw T. L., \& Cohen, A. S. (2014). Life satisfaction as a distinguishing indicator or college student functioning: Further validation of the two-continua model of mental health. Social Indicators research, 117, 319-334.

Ryff, C. D. (1995) Psychological well-being in adult life. Current Directions in Psychological Science, 4(4), 99-104.

Ryff, C., \& Singer, B. (1998). The contours of positive human health. Psychological Inquiry, 9, 128. 


\section{Acta Educationis Generalis \\ Volume 11, 2021, Issue 2}

Suldo, S. M., \& Shaffer, E. J. (2008). Looking beyond psychopathology: The dual-factor model of mental health in youth. School Psychology Review, 37, 52-68.

Tamášová, V., \& Kušnieriková, Z. (2018). Emocionalita v rodine ako významný factor wellbeingu stredoškolákov. In Gajdošová, E. et al. (Eds.), Duševné zdravie a wellbeeing virtuálnej generácie (pp. 32-47). Bratislava: IPčko.

Telef, B. B., \& Furlong, M. J. (2017). Social and emotional psychological factors associated with subjective well-being: A comparison of Turkish and Californian adolescents. Cross Cultural Research, 51(5), 491-520.

Timofejová, T., Svence, G., \& Petrulite, A. (2016). Theoretical and practical study of the concept of social and emotional health by Michael J. Furlong applied to the selection of teenagers and youth. Signum Temporis, 8(1), 67-75.

Vázquez, C., Hervás, G., Rahona, J. J., \& Gómez, D. (2009). Psychological well-being and health. Contributions of positive psychology. Annuary of Clinical and health Pschology, 5, 15-27.

WHO (2004). Promoting Mental Health: Concepts, Emerging Evidence, Practice: Summary report. Geneva: World Health Organisation.

You, S., Furlong, M. J., Dowdy, E., Renshaw, T. L., Smith, D. C., \& O’Malley, M. D. (2013). Further validation of the Social and Emotional Health Survey for high school students. Applied Research in Quality of Life, 9(4), 997-1015. 